\title{
ANALYSIS OF THE SEISMIC PERFORMANCE OF A TWO-STOREY LOG HOUSE
}

Jorge M. Branco a , Paulo B. Lourenço ${ }^{\mathrm{b}}$, Chrysl A. Aranha ${ }^{\mathrm{c}}$

aAssistant Professor, ISISE, Univ. of Minho, Dept. of Civil Engineering, Campus de Azurém, 4810-058 Guimarães, Portugal.

Tel. +351253510 200; Fax: +351253510217

E-mail: jbranco@ civil.uminho.pt; Corresponding author

${ }^{b}$ Full Professor, ISISE, Univ. of Minho, Dept. of Civil Engineering

E-mail: pbl@ civil.uminho.pt

${ }^{\mathrm{c}} \mathrm{PhD}$ student, ISISE, Univ. of Minho, Dept. of Civil Engineering

E-mail: chryslaranha@gmail.com

\begin{abstract}
The dearth of knowledge on the load resistance mechanisms of log houses and the need for developing numerical models that are capable of simulating the actual behaviour of these structures has pushed efforts to research the relatively unexplored aspects of log house construction. The aim of the research that is presented in this paper is to build a working model of a log house that will contribute toward understanding the behaviour of these structures under seismic loading. The paper presents the results of a series of shaking table tests conducted on a log house and goes on to develop a numerical model of the tested house. The finite element model has been created in SAP2000 and validated against the experimental results. The modelling assumptions and the difficulties involved in the process have been described and, finally, a discussion on the effects of the variation of different physical and material parameters on the results yielded by the model has been drawn up.
\end{abstract}

Keywords: timber structures, seismic engineering; log houses; shaking table tests. 


\section{Introduction}

The modern timber housing industry mostly revolves around light timber-framed structures and more recently, solid timber construction, which has been made possible due to the development of novel engineered wood products. However, in colder countries with thickly forested areas, traditional timber structures in the form of log houses are built even today. Although log house construction is one of the oldest forms of construction, there is still a scarcity of knowledge regarding the three-dimensional response of the log house system, especially in terms of its load resistance mechanisms and seismic behaviour.

Most of the research campaigns on log houses have focused on investigating the lateral load resistance mechanisms of individual log walls (Hirai et al., 2004; Branco \& Araujo, 2012). As seen in the quasi-static tests conducted by Popovski (2002) on log walls with varied configurations, friction has been found to contribute to the lateral load resistance of $\log$ walls. The influence of friction on the lateral load carrying capacity was most evident in the log walls without connectors and crosswall corners. However, the contribution of friction is not taken into account in building codes because of the complexity involved in its quantification (Hirai et al., 2008). The vertical component of the earthquake ground motion provides a variation in the value of frictional resistance, which makes it even harder to determine the role played by friction during seismic events.

Owing to the inadequate understanding of the behaviour of log houses, developing sophisticated models of these structures is difficult. Although efforts have been directed towards developing finite element models of the individual components of log houses like the walls, foundation connections and mechanical fasteners, numerical models of entire structures are hard to come across. Due to this, there is a certain degree of unpredictability associated with the seismic performance of log houses. Scott et al. (2005)

developed a 2D finite element model of a log shear wall as well as a sill log-foundation model. The accuracy of the models was verified by comparing their results with those obtained from the experiments conducted by Gorman and Shreshta (2002) on log shear walls and prior tests on log-log friction and sill log-foundation connections (Scott, 2003).

Since $\log$ structures are strong and log walls have a good energy dissipation capacity due to their deformability (Popovski, 2002), their potential could be tapped and taken advantage of in seismic regions. With the view of increasing the understanding of the seismic performance of log houses, the University of Minho, in partnership with the Portuguese company, Rusticasa ${ }^{\circledR}$, carried out a series of experiments 
together with numerical studies. Seismic tests were done within the framework of the SERIES (Seismic Engineering Research Infrastructures for European Synergies) project on 'Multi-storey timber buildings'.

The current paper builds on papers which presented the results of the preliminary analysis of the shaking table tests on the log house and dealt with the pre-design of the shaking table tests (Branco et al., 2013; Branco et al., 2014). The main focus of the present paper is the proposed numerical model of the log house which differed from the model used in the prediction of the behaviour of the specimen. The geometry of the model created during the test pre-design process was approximate, assumed a uniform distribution of the additional masses and differed in the definition of the OSB panels for the floor and roof. In the numerical model described in this paper, the geometry and loading are accurately defined, the influence of mechanical properties and the effects of adding links to simulate crosswall connections and other mechanical connectors have been discussed.

\section{Description of the $\log$ house specimen}

With a rectangular plan of $5.64 \mathrm{~m} \times 7.3 \mathrm{~m}$ and ridge height of $5.28 \mathrm{~m}$, the adopted house represents a typical log construction designed by Rusticasa ${ }^{\circledR}$. The walls are formed by stacking logs one over the other, with their tongue and groove profiles facilitating a perfect fit. The cross-walls are formed by halved joints at the location of the corner notches. To further strengthen the connection, 8mm diameter self-tapping screws are provided between adjacent log courses.

The lamellas of the glulam logs are made of Scots Pine (Pinus sylvestris L.) categorized as C24 strength class in accordance with EN 388:2009. The mechanical properties of the lamellas were obtained using the procedures outlined in EN 1194:1999 (Branco \& Cruz, 2008). The outer walls of the log house are two times thicker than the internal walls and their dimensions can be seen in Figure 1. The logs of the internal walls form dovetail joints with their counterparts in the exterior walls at the intersections. The rigid in-plane behaviour of the roof and floor is guaranteed by $22 \mathrm{~mm}$ thick Oriented Strand Board (OSB) studded panels. Mechanical fasteners in the form of self-tapping screws measuring $8 \mathrm{~mm}$ in diameter and $140 \mathrm{~mm}$ in length are provided around all the doors and windows. 

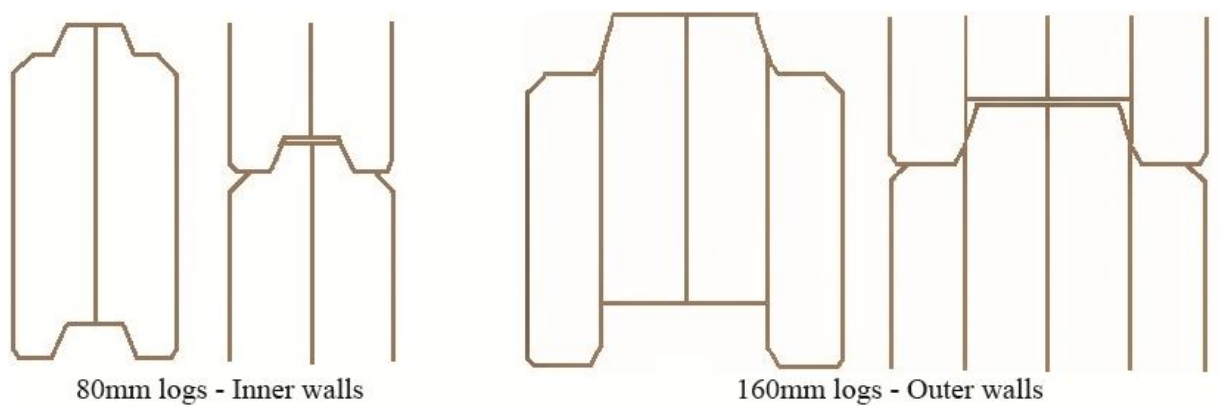

Figure 1- Dimensions of the logs in the internal walls (left) and external walls (right)

The determination of the additional load needed to simulate the floor and roof loads in reality, was calculated taking into consideration the typical floor and roof layout of the log houses designed by Rusticasa ${ }^{\circledR}$. The total weight of the floor excluding the OSB panels is found to be $6.215 \mathrm{kN}$. The components of the floor that were taken into consideration were as follows:

- a floating wood floor layer (16mm);

- $\quad$ an insulating layer $(45 \mathrm{~mm})$;

- $\quad$ planking (8mm).

Considering an accidental load value of $2 \mathrm{kN} / \mathrm{m} 2$, the additional floor load is calculated to be 25.657kN. In the $\log$ house tested at the National Laboratory of Civil Engineering (LNEC), four steel platforms having a mass of $600 \mathrm{~kg}$ each were placed on the inter-storey floor as additional masses.

In order to calculate the additional loads on the roof, the following components were considered:

- clay tiles;

- ventilation strips;

- $\quad$ planking $(8 \mathrm{~mm})$;

- $\quad$ insulating layer $(22 \mathrm{~mm})$.

The total weight of the roof covering was found to be $21.2 \mathrm{kN}$. The accidental load value was taken as 0 as snow loads are not considered. In the log house that was tested, 398 steel plates, each having a mass of $7.1 \mathrm{~kg}$, were fastened onto the OSB panels of the roof to simulate the roof covering used in real-life. The weight of the individual components of the building as well as the total weight is computed in Table 1.

Figure 2 shows a 3D model of the log house with the position of the mechanical fasteners marked. 
Table 1- Calculation of the total weight of the log house

\begin{tabular}{lccc}
\hline \hline Components & Density $\left(\mathbf{k N} / \mathbf{m}^{3}\right)$ & Volume $\left(\mathbf{m}^{\mathbf{3}}\right)$ & Weight $(\mathbf{k N})$ \\
\hline \hline Exterior walls & 4.9 & $114.89 * 0.16=18.382$ & 90.062 \\
Interior walls & 4.9 & $45.514 * 0.08=3.641$ & 17.841 \\
Floor joists & 4.9 & $12.66 * 0.09=5.582$ & 7.583 \\
Rafters & 4.9 & $20.748 * 0.07=1.452$ & 1.011 \\
Ridge beam & 4.9 & $1.72 * 0.12=0.206$ & 6.266 \\
OSB -floor & 6.1 & $46.688 * 0.022=1.027$ & 4.349 \\
OSB -roof & 6.1 & $32.404 * 0.022=0.713$ & 23.544 \\
Additional weight-floor & - & - & 26.75 \\
Additional weight-roof & - & - & 182.523 \\
\hline Total weight & & & \\
\hline
\end{tabular}

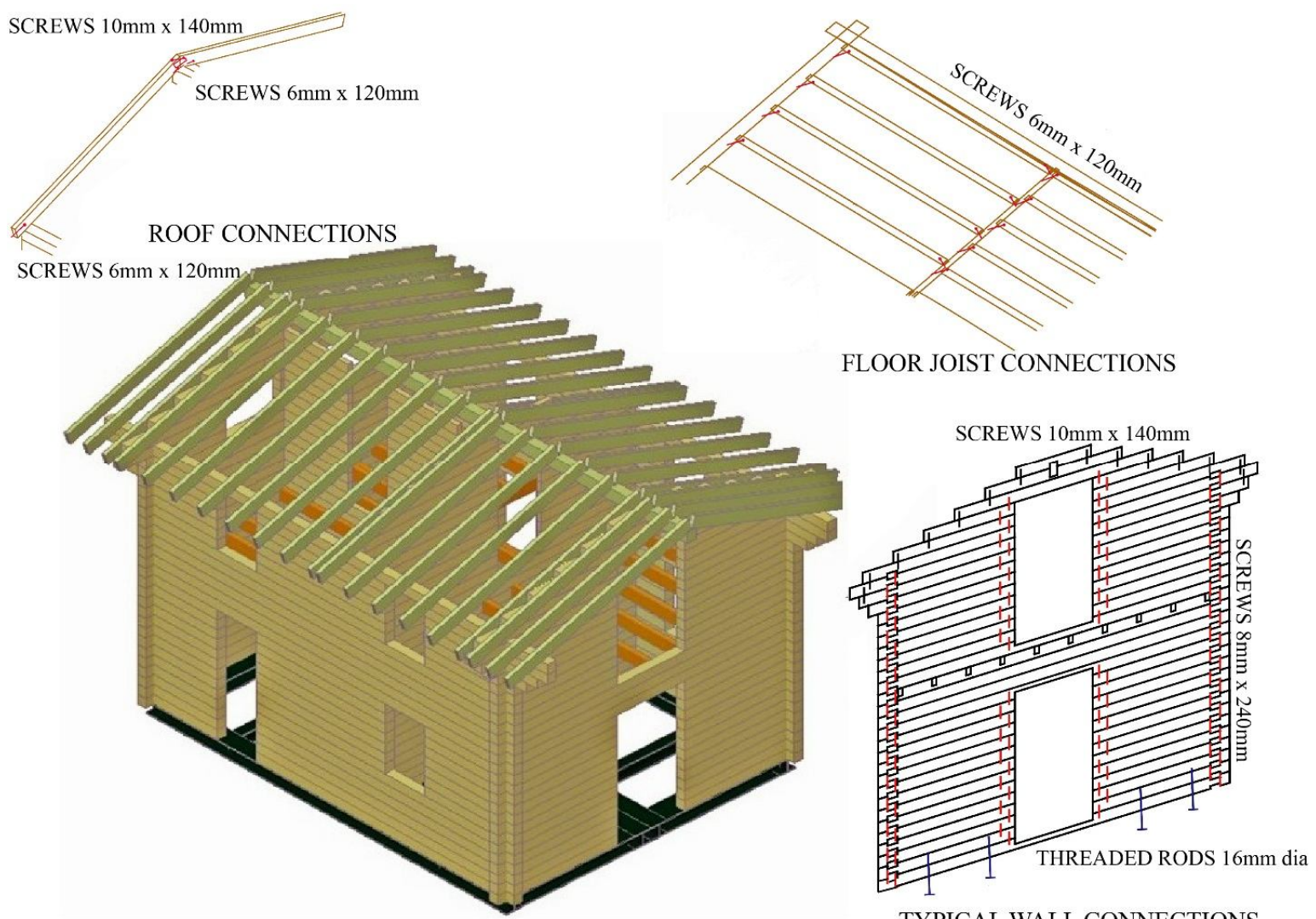

Figure 2- The structure of the log house and the distribution of the mechanical fasteners 
Since the dimensions of the shaking table at the LNEC, Portugal, did not meet the requirements of the building, a lattice of steel beams was mounted over the table to provide a wide enough base. The sill logs are connected to the foundation (steel lattice in this case) through M16 bolts of class 8.8 that are spaced $0.5 \mathrm{~m}$ apart. The sill log-foundation connection is rigid to ensure that sliding is minimal. The detailed description of the geometry of the house and the components is contained in Branco et al. (2014).

The construction of the house was done by just three workers in a span of four days. The reason for the swiftness of the construction is because the logs for the walls, floor and roof, along with the OSB panels, were prefabricated in a factory at Vila Nova de Cerveira, located about 400km away from Lisbon. In Figure 3, the fully completed two-storey duo-pitch log house is seen.

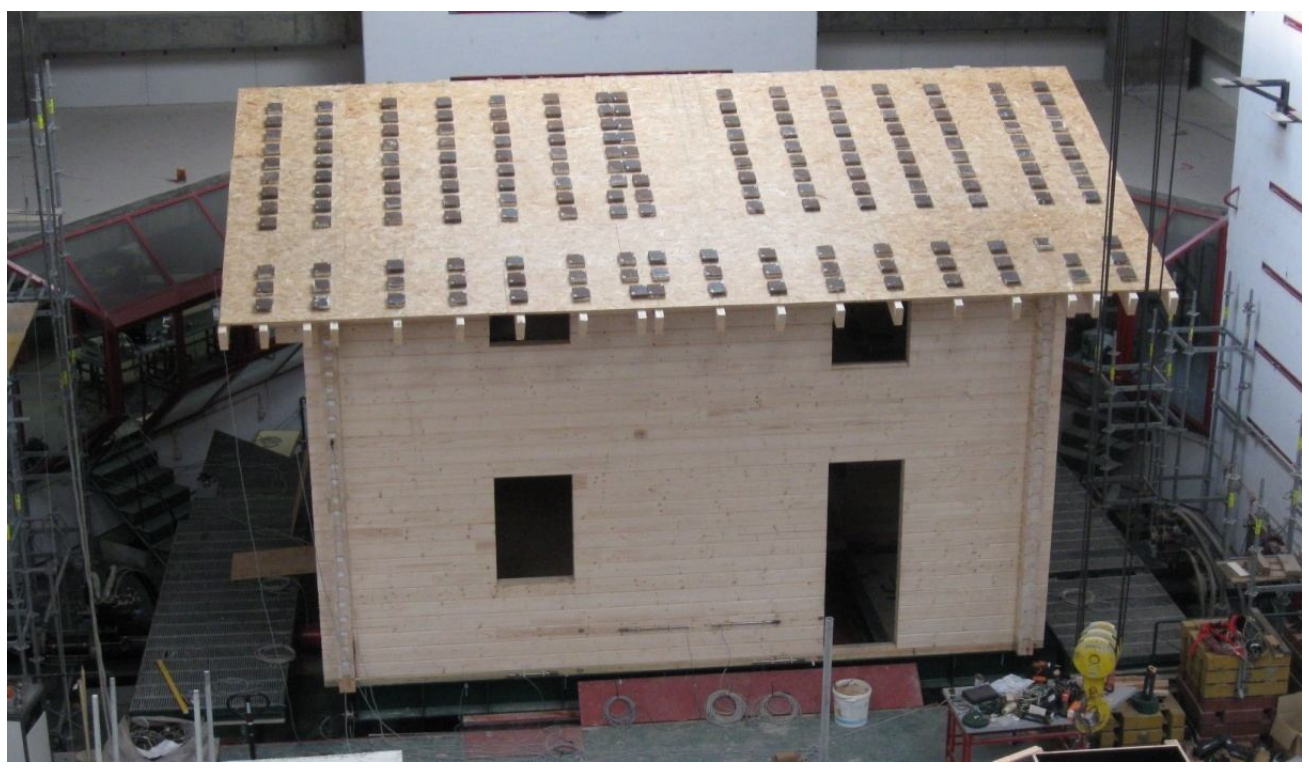

Figure 3-The fully assembled house on the shaking table

\section{Testing process}

In order to measure the accelerations, forces and displacements in the building, a total of 81 instruments were placed at different points of interest across the building. The sampling frequency of all the instruments was $125 \mathrm{~Hz}$. Linear variable differential transformer (LVDTs) were used to measure the slippage, uplift, shear and sliding of the walls at the ground floor level. The magnitude of the inter-storey displacement was recorded by LVDTs mounted at the openings of the interior walls. Two accelerometers were used to record the accelerations of the shaking table in the longitudinal and transverse directions. Accelerometers were also placed at the roof level and inter-storey floor level for cross-wall intersections 
and at mid height of the interior walls. An optical acquisition system consisting of infrared cameras and linear position sensors was used to continuously detect and measure absolute displacement of the control points, which are the so-called Hamamatsu system transducers. Figure 4 shows the LVDTs used to monitor the various deformations in the building.

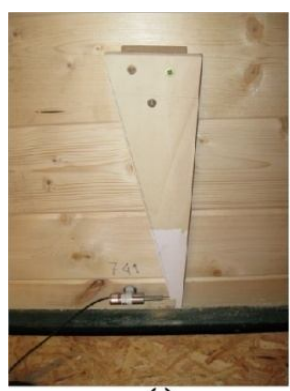

(a)

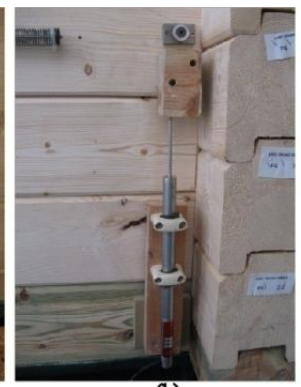

(b)

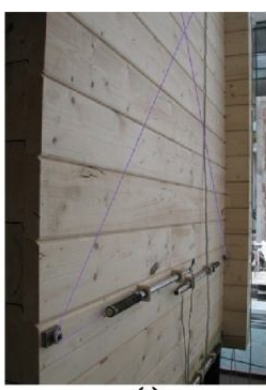

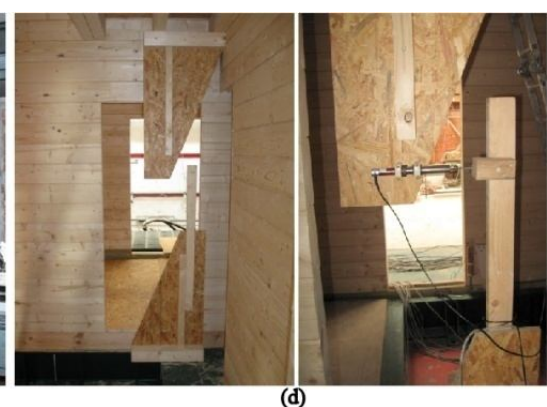

Figure 4- LVDTs for measuring (a) slippage (b) uplift (c) shear deformation (d) inter-storey

\section{displacement}

Once the building was constructed and the instruments were set-up, the testing went as per the following procedure: i) tuning the system (at every stage); ii) dynamic characterization (before and after every seismic test) where the input was in the form of white noise; and, iii) seismic tests.

The input signal for the seismic tests was the one that was registered at the Ulcinj- Hotel Albatros during the Montenegro earthquake that took place on the $15^{\text {th }}$ of April, 1979. Figure 5 shows the unscaled acceleration time history functions that were used in the shaking table tests.

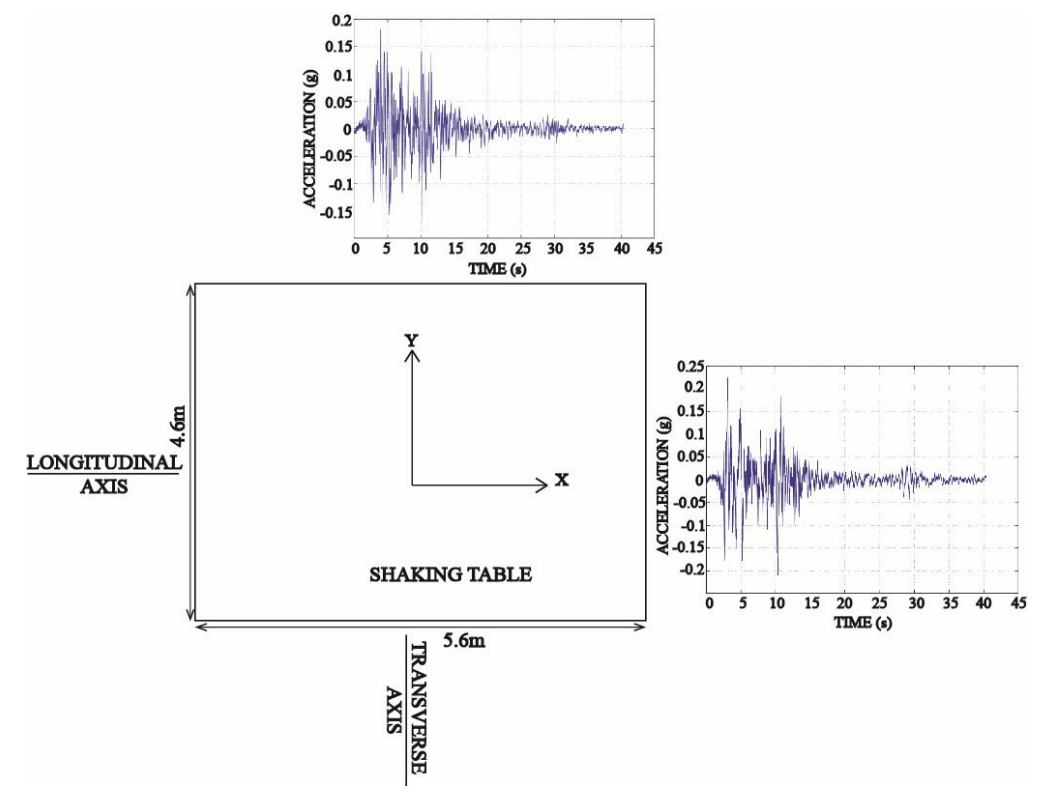

Figure 5-The unscaled acceleration time history inputs in the longitudinal and transverse direction 
The seismic testing was carried out with three different peak ground acceleration (PGA) values $0.07 \mathrm{~g}, 0.28 \mathrm{~g}$ and $0.5 \mathrm{~g}$, scaling the previously defined accelerograms. During this incremental test procedure, whenever damage occurred, an identification test using white noise as input was performed to assess any variation in the fundamental period of the house. No repairs were carried out any stage.

\section{Results}

From the series of dynamic characterization tests performed on the structure, information regarding the frequencies, mode shapes, inter-storey drift and hold down forces was obtained. The modal analysis was carried out using ARTeMIS (2013) and the data obtained from the rest of the monitoring instruments was processed in LNEC-SPA (Mendes, 2009).

\subsection{Modal analysis}

Input-output modal identification techniques were used to process the data recorded from the accelerometers placed on the shaking table and the accelerometers placed in the house. An anti-aliasing filter was used to remove the frequency content above the Nyquist frequency $(62.5 \mathrm{~Hz})$ and a Hanning window was used to overcome problems due to leakage. In the spectral analysis configuration, the overlap was set to $66.7 \%$. Only the first four experimentally observed modes of the structure were identified and evaluated.

According to Eurocode 8 (2004), provided the criteria of regularity in plan and elevation are fulfilled, the fundamental period, $T_{\mathrm{o}}$, of a building with height $H$, can be estimated by the formula:

$$
T_{o}=0.05 H^{0.75}
$$

For the $\log$ house, $\mathrm{H}=5.28 \mathrm{~m}$. Therefore the predicted value of $\mathrm{T}_{\mathrm{o}}$ is $0.174 \mathrm{~s}$. The fundamental period obtained experimentally was $0.186 \mathrm{~s}$.

The fundamental period obtained during the initial characterization test was $0.186 \mathrm{~s}[\mathrm{f}=5.39 \mathrm{~Hz}]$ and increased to $0.196 \mathrm{~s}[\mathrm{f}=5.11 \mathrm{~Hz}]$ during the final characterization test (after the entire series of tests performed). This slight increase in the fundamental period value confirms that the log-house did not suffer any major damage. The other three modes showed negligible increments in the value of their natural periods. The periods of the first four modes have been determined from the characterization tests conducted (i) at the start of the testing procedure, (ii) after the seismic tests with PGA of $0.07 \mathrm{~g}$, (iii) after the seismic tests with PGA of $0.28 \mathrm{~g}$, and (iv) after the seismic tests with PGA of $0.5 \mathrm{~g}$. 
All modes captured are translational and were common to the rest of the characterization tests. The placement of the accelerometers in the house and the experimental mode shapes are seen in Figure 6. The first mode has a single curvature in both main directions while the second mode has a single curvature in the X-direction. The third and fourth modes are characterized by a double curvature in the X-and Ydirections, respectively.
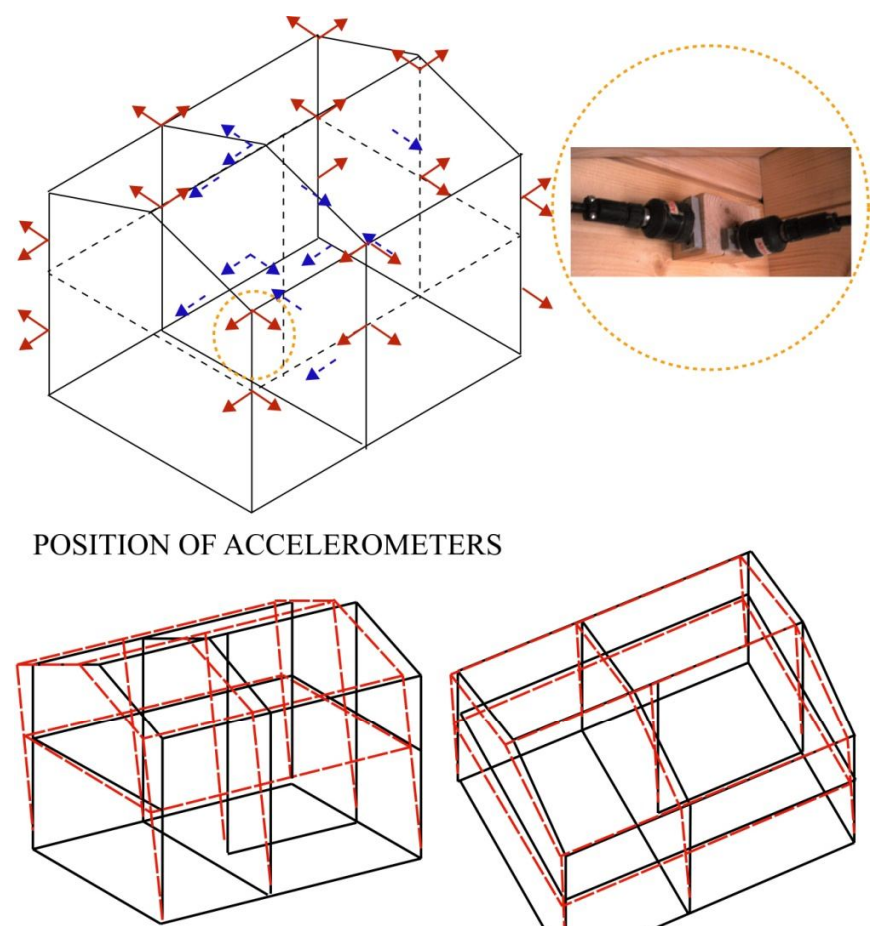

MODE 1: $\mathrm{T}=0.186 \mathrm{~s}$
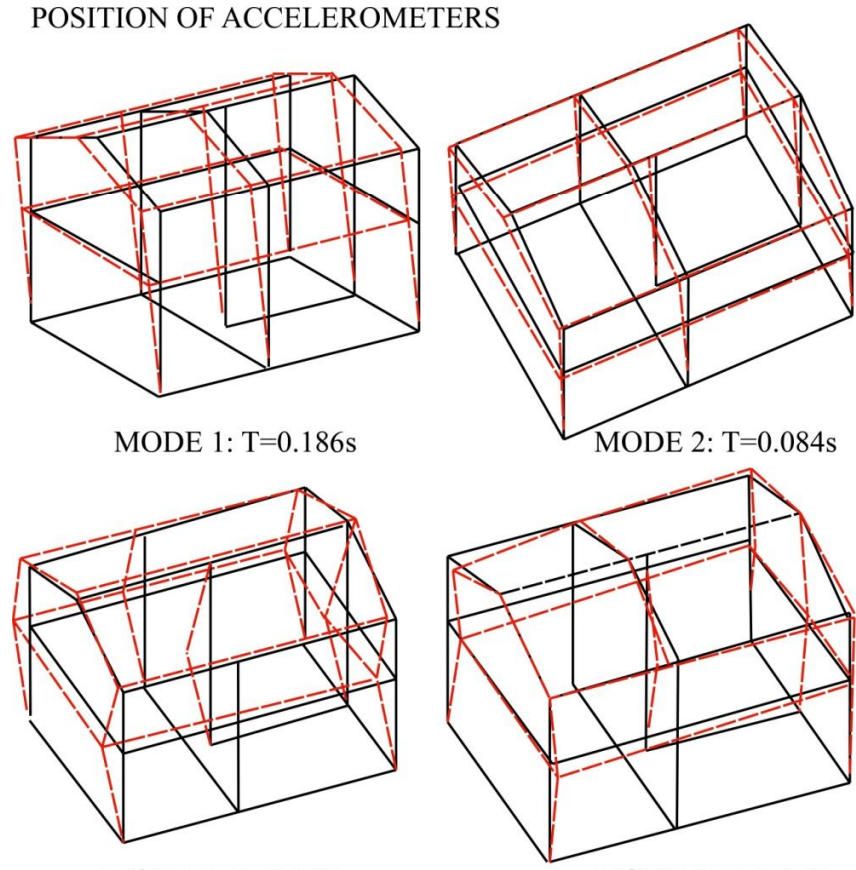

MODE 3: $\mathrm{T}=0.067 \mathrm{~s}$

MODE 4: $\mathrm{T}=0.049 \mathrm{~s}$

Figure 6- Locations of the accelerometers and the mode shapes observed during the tests

Table 2 enlists the values of the natural periods of the first four modes for each of the dynamic characterization tests mentioned above. 
Table 2-Natural periods[s] of the log house tested

\begin{tabular}{lcccc}
\hline Mode no. & Before 0.07g & After 0.07g & After 0.28g & After 0.50g \\
\hline 1 & 0.186 & 0.188 & 0.193 & 0.196 \\
2 & 0.084 & 0.085 & 0.085 & 0.087 \\
3 & 0.067 & 0.067 & 0.067 & 0.068 \\
4 & 0.049 & 0.049 & 0.049 & 0.05 \\
\hline
\end{tabular}

\subsection{Inter-storey drift}

The relative displacement between the floors was measured by LVDTs whereas the optical acquisition system measured the absolute displacement. The sensors of the optical acquisition system were placed at the ground level, inter-storey floor level, the roof level as well as at mid-height of the cross wall intersection $\mathrm{C} 1$ (see Figure 7 for the location) on both the floors. After processing the data obtained from the tests and comparing the displacements obtained from both the measurement systems, it was found that the values differed vastly. Since it is known that the optical acquisition system gives accurate measurements and the LVDTs are extremely sensitive, only the displacements measured by the LEDs of the optical acquisition (Hamamatsu) system have been used to compute the maximum inter-storey drift. The values of the inter-storey drift expressed in terms of percentage are enlisted in Table 3. The values of inter-storey drift were highest for the tests with 0.5g PGA, but are well within the $1 \%$ limit prescribed by EC 8 (2004).
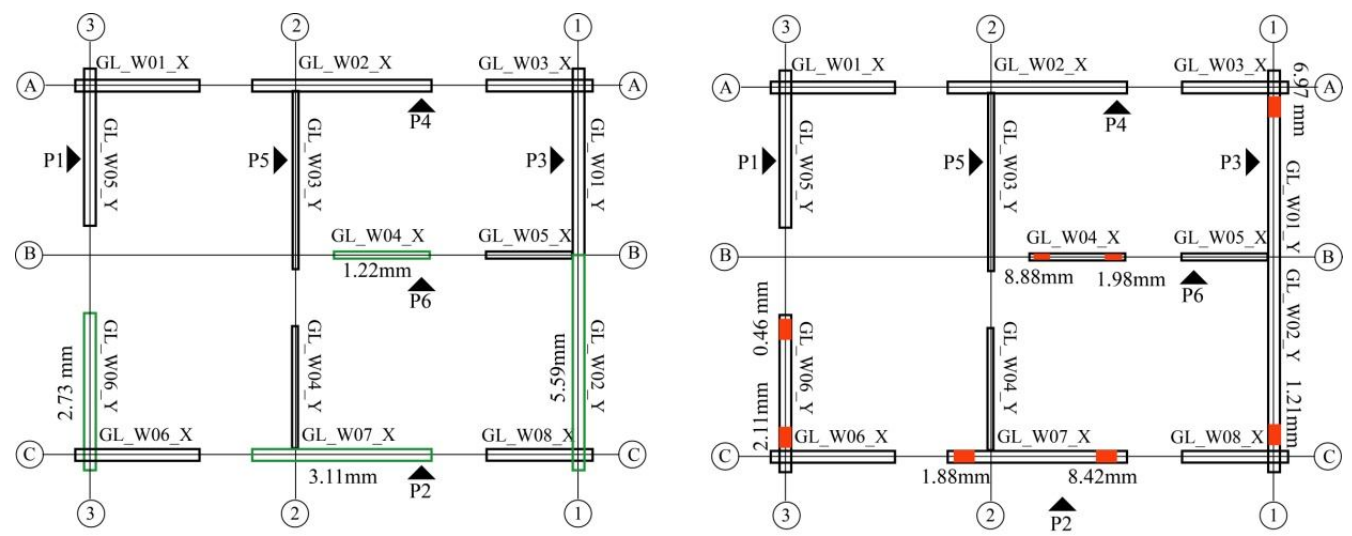

Figure 7- Maximum values of wall slippage (left) and uplift (right) observed during the tests of $0.5 \mathrm{~g}$

PGA 
Table 3- Maximum inter-storey drift values expressed in \%

\begin{tabular}{lccc}
\hline P.G.A. & $\mathbf{0 . 0 7}$ & $\mathbf{0 . 2 8 g}$ & $\mathbf{0 . 5 9}$ \\
\hline Inter-storey drift at the level of the first floor & 0.001 & 0.007 & 0.07 \\
Inter-storey drift at roof level & 0.001 & 0.004 & 0.01 \\
\hline
\end{tabular}

\subsection{Wall deformations}

There was no observable damage during the tests of $0.07 \mathrm{~g}$ PGA. The only damage that was noticed after the tests with 0.28g PGA was the sliding of the logs in the North Western corner (C1) of the house, located near the window in wall P3(refer to Figure 7 for the wall designation). The minor damages that were observed after the PGA was increased to $0.5 \mathrm{~g}$ were the fracture along the length of the log due to outof-plane flexure, slippage of logs due to shear, fracture along the grain at connections between orthogonal walls due to shear, internal cracks in the log section and fracture at the top and bottom notches of the logs.

In the tests with a PGA of $0.07 \mathrm{~g}$, the values of shear deformation, slippage and wall uplift values were negligible. The magnitude of shear was low at all the measured points even for the tests with a PGA of $0.28 \mathrm{~g}$ and $0.5 \mathrm{~g}$. The highest value of wall slippage during the tests of $0.28 \mathrm{~g}$ and $0.5 \mathrm{~g}$ was recorded by the LVDT that was placed at the base of the western wall (GLW02_Y), closer to the north-west corner, where a pronounced sliding between the logs in the upper floor was seen (refer Figure 7 for the wall orientations in the building plan). The values of wall uplift were very low even for the tests of $0.28 \mathrm{~g}$. The highest value of wall uplift was 9mm, which was recorded by the LVDT at the internal wall GLW04_X during the $0.5 \mathrm{~g}$ test. The wall uplift and slippage values that were obtained after processing the data obtained during the tests of $0.5 \mathrm{~g}$ are presented in Figure 7.

\section{Finite element model}

A 3-D finite element model of the log house was developed using SAP2000 (CSI, 2011). This model differed from the one developed during the pre-design phase of the experimental campaign (Branco et al., 2014) in the following aspects: i) definition of material properties of Scots Pine wood; ii) accurate geometry and definition of additional masses; and, iii) modelling of OSB wall and roof panels.

\subsection{Description of the model}

The logs were modelled with shell elements of $0.08 \mathrm{~m}$ thickness for the interior walls and $0.16 \mathrm{~m}$ thickness for the exterior walls. The floor beams, the rafters and the ridge beam were modelled as frame 
elements. The OSB panels were modelled as shell elements of $22 \mathrm{~mm}$ thickness. The additional floor loads were distributed on the inter-storey floor shell elements according to their placement in the log house. The roof loads were distributed uniformly along the rafters. The interlocking cross wall connections were not explicitly modelled. There is not much information available on the yielding behaviour of the connectors between the log courses, working as a group, under seismic loads. Hence, the log house was simplified into a structure with a box-like behaviour. In order to ensure the rigid in-plane behaviour of the floor and the roof, diaphragm constraints were provided at the corners of the floor beams and rafters. The 3D numerical model is presented in Figure 8.

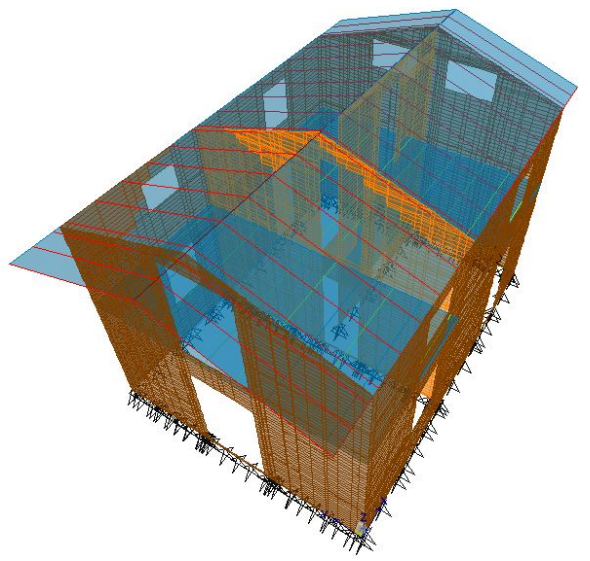

Figure 8- Finite element model of the log house created in SAP2000 (CSI, 2011).

Since wood is a material with three mutually perpendicular planes of symmetry, it is best defined as an orthotropic material. From the experiments performed by Rusticasa ${ }^{\circledR}$ during log production, the density of wood was taken to be $500 \mathrm{~kg} / \mathrm{m}^{3}$. In the experiments done by Branco and Cruz (2008), the value obtained for $\mathrm{E}_{\mathrm{L}}$ for the specimens with cross section $80 \times 150 \mathrm{~mm}^{2}$ was $10760 \mathrm{MPa}$ and the specimens with cross section $160 \times 150 \mathrm{~mm}^{2}$ yielded an average $\mathrm{E}_{\mathrm{L}}$ value of $12350 \mathrm{MPa}$. Owing to the fact that the tests results obtained on that prior step of the research are close to the value prescribed in National documentation, the modulus of elasticity in the longitudinal direction, $\mathrm{E}_{\mathrm{L}}$, was taken as $11760 \mathrm{MPa}$, as suggested by the document on the mechanical properties of softwoods published by LNEC(Machado and Monteiro, 1997). The relations for the radial modulus of elasticity $E_{R}$, for the tangential modulus of elasticity $E_{T}$ and the shear modulus $\mathrm{G}_{\mathrm{LT}}$, have been taken from DIN 68364 (1979), while the relation for the other shear moduli, namely $\mathrm{G}_{\mathrm{LR}}$, has been taken from Bodig and Jane (1982) and, $\mathrm{G}_{\mathrm{RT}}$ has been taken from(Bucur, 2006). For the OSB panels, the values of the elastic moduli were obtained from the supplier's manual and the shear modulus 
was taken from EN 12369-1(2001).The values of the moduli of elasticity, Poisson's ratio and shear moduli that were used to define the properties of the Scots Pine log and the OSB panels are presented in Table 4.

Table 4-Elastic properties of the materials used in the model

\begin{tabular}{llcc}
\hline \hline & \multicolumn{2}{c}{ Scots Pine log properties } & \\
\hline \hline Modulus of elasticity, E (MPa) & $\mathrm{E}_{\mathrm{L}}=11760$ & $\mathrm{E}_{\mathrm{R}}=1069$ & $\mathrm{E}_{\mathrm{T}}=534.5$ \\
Shear modulus, G (MPa) & $\mathrm{G}_{\mathrm{RT}}=77.4$ & $\mathrm{G}_{\mathrm{LT}}=683.7$ & $\mathrm{G}_{\mathrm{LR}}=725.9$ \\
Poisson's ratio, $v$ & $v_{\mathrm{RT}}=0.3$ & $v_{\mathrm{LT}}=0.3$ & $v_{\mathrm{LR}}=0.3$ \\
\hline & \multicolumn{2}{c}{ OSB properties } & \\
\hline \hline Modulus of elasticity, $\mathrm{E}(\mathrm{MPa})$ & $\mathrm{E}_{\mathrm{L}}=4600$ & $\mathrm{E}_{\mathrm{R}}=1900$ & $\mathrm{E}_{\mathrm{T}}=1900$ \\
Shear modulus, $\mathrm{G}(\mathrm{MPa})$ & $\mathrm{G}_{\mathrm{RT}}=1080$ & $\mathrm{G}_{\mathrm{LT}}=1080$ & $\mathrm{G}_{\mathrm{LR}}=1080$ \\
Poisson's ratio, $v$ & $v_{\mathrm{RT}}=0.3$ & $v_{\mathrm{LT}}=0.3$ & $v_{\mathrm{LR}}=0.3$ \\
& & & \\
\hline
\end{tabular}

\subsection{Comparison of numerical and experimental results}

The validity of the numerical model was assessed by comparing the numerical values with the tests results of the natural periods, the mode shapes and the variation in the displacement of the joints where the Hamamatsu sensors were placed.

The natural periods of the first two modes of the numerical model are very closely spaced. This may be due to the fact that they correspond to the first observed mode of the log house, which had translational motion taking place in the longitudinal as well as the transverse direction. The subsequent mode of the numerical model of the log house showed a very good agreement with the second mode obtained experimentally, with a MAC (modal assurance criterion) value of 0.95 and a $6 \%$ difference in the period (Table 5). No mode shape of the numerical model corresponded to the double curvature mode in the longitudinal direction. Instead, the numerical model revealed some modes that were not observed during the experimental tests $-\mathrm{a}$ torsional mode with a period of $0.158 \mathrm{~s}$ and some local modes. The formation of local modes was due to the out-of-plane deformation at the free end of the internal wall P6 or localized deformations at the roof level and involved negligible movement of the rest of the structure. The mode that was characterized by a double curvature movement in the transverse direction showed lesser congruence compared to the other two modes with a MAC value of 0.77 and a $12.2 \%$ difference in the estimation of the period. 
The average error in the period is about $8 \%$ for the three modes considered with an average MAC value of 0.91 . The translational degrees of freedom of the same 26 points of interest in the experimental and the numeric mode shapes were used to compute the MAC. The values of the natural periods obtained that are relevant for comparison with the experimental values can be seen in Table $\mathbf{5}$ and the mode shapes are seen in Figure 9. The table also presents a comparison with the experimental values of the natural periods of the log house. Table 6 provides the percentage of mass participation values for each of the experimental modes, which demonstrate that about $90 \%$ of the mass is involved in the modes captured.

Table 5- Comparison of the experimental and numerical values of the natural periods and mode shapes

\begin{tabular}{|c|c|c|c|c|c|c|}
\hline \multirow[b]{2}{*}{ Mode no. } & \multicolumn{2}{|c|}{ Numerical Model } & \multicolumn{2}{|c|}{ Experimental } & \multirow[b]{2}{*}{$\%$ Error } & \multirow[b]{2}{*}{ MAC } \\
\hline & Mode shape & Period (s) & Mode shape & Period (s) & & \\
\hline 1 & Translation-Y & 0.192 & $\begin{array}{l}\text { Translation } \\
\text { along } X \text { and }\end{array}$ & 0.186 & 3.7 & 0.94 \\
\hline 2 & Translation-X & 0.190 & Y & & 2.7 & 0.98 \\
\hline 3 & Translation- $X$ & 0.079 & $\begin{array}{c}\text { Translation- } \\
\text { X }\end{array}$ & 0.084 & 6 & 0.95 \\
\hline 4 & Translation-Y & 0.043 & $\begin{array}{c}\text { Translation- } \\
\text { Y }\end{array}$ & 0.049 & 12.2 & 0.77 \\
\hline
\end{tabular}

Table 6- Modal mass participation in \%

\begin{tabular}{lcc}
\hline \hline Mode no. & $\begin{array}{c}\text { Mass participation along the X- } \\
\text { direction }\end{array}$ & $\begin{array}{c}\text { Mass participation along the Y- } \\
\text { direction }\end{array}$ \\
\hline \hline 1 & 2.3 & 81.7 \\
2 & 81.7 & 2.3 \\
3 & 7.7 & 0.0 \\
4 & 0.0 & 6.0 \\
Cumulative mass participation & $\mathbf{9 1 . 7}$ & $\mathbf{9 0}$ \\
\hline
\end{tabular}




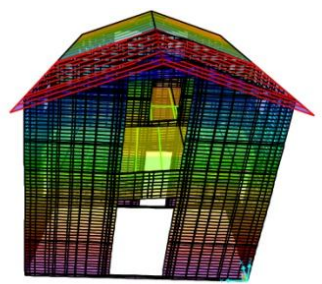

$\mathrm{T}=0.192 \mathrm{~s}$

$\mathrm{b}$

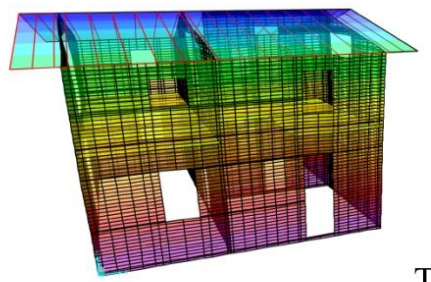

$\mathrm{T}=0.190 \mathrm{~s}$

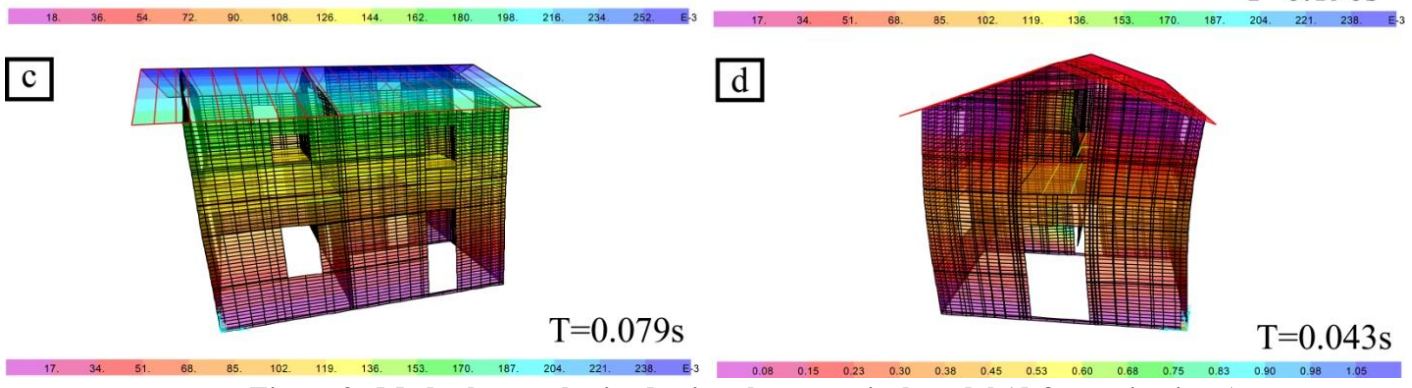

Figure 9-Mode shapes obtained using the numerical model (deformation in $\mathbf{m}$ )

The experimental and analytical variations in the values of absolute displacement at certain joints were plotted for the test with the PGA of $0.5 \mathrm{~g}$. The joints that were taken into consideration were the ones corresponding to the positions of the optical sensors at the base, mid-height and the top of the cross-wall intersection of the walls P2 and P3 (see Figure 7 for the walls designation). The graphs of the displacement time histories obtained experimentally and numerically have been plotted and are presented in Figure $\mathbf{1 0 .}$ The agreement in the values of the natural periods, mode shapes and MAC values as well as the results of the comparison of displacements demonstrate the adequacy of the adopted numerical model. 

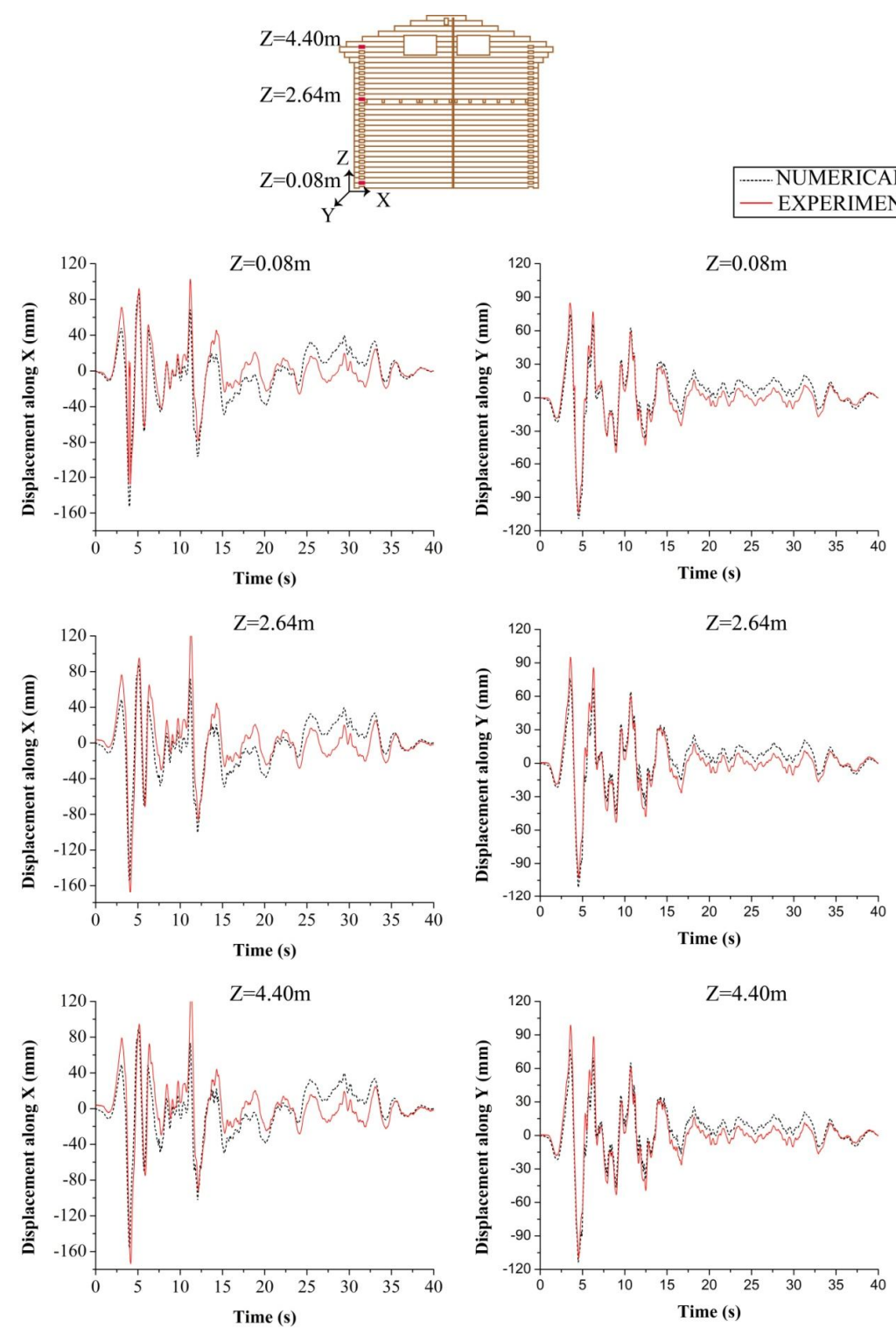

Figure 10- Comparison between experimental and numerical values of absolute displacements along the intersection of walls P2 and P3

\subsection{Sensitivity analysis}

In the preliminary stages of developing the numerical model, the material properties of the glulam logs were defined using the values prescribed by EN338 (2009). According to this standard, for timber of strength class $\mathrm{C} 24$, the value of the modulus of elasticity measured parallel to grain $\left(\mathrm{E}_{\mathrm{L}}\right)$ is $11000 \mathrm{MPa}$, the modulus of elasticity measured perpendicular to grain $\left(E_{R}\right.$ and $\left.E_{T}\right)$ is $370 \mathrm{MPa}$ and the value of the shear modulus $(\mathrm{G})$ is 690MPa in all three directions. The value of Poisson's ratio was set to 0.3. On completion of the modal analysis, it was found that the shell elements of the walls underwent in-plane distortion and 
the magnitude of the out-of-plane deformations around the wall openings was unrealistically high. To demonstrate the typical deformation pattern of the log walls, the movement of the house during the first mode has been captured and is presented in Figure 11. The value of $\mathrm{E}_{\mathrm{L}}$ and the radial-tangential shear modulus $\mathrm{G}_{\mathrm{RT}}$ were found to have a significant influence on the behaviour of the log walls.

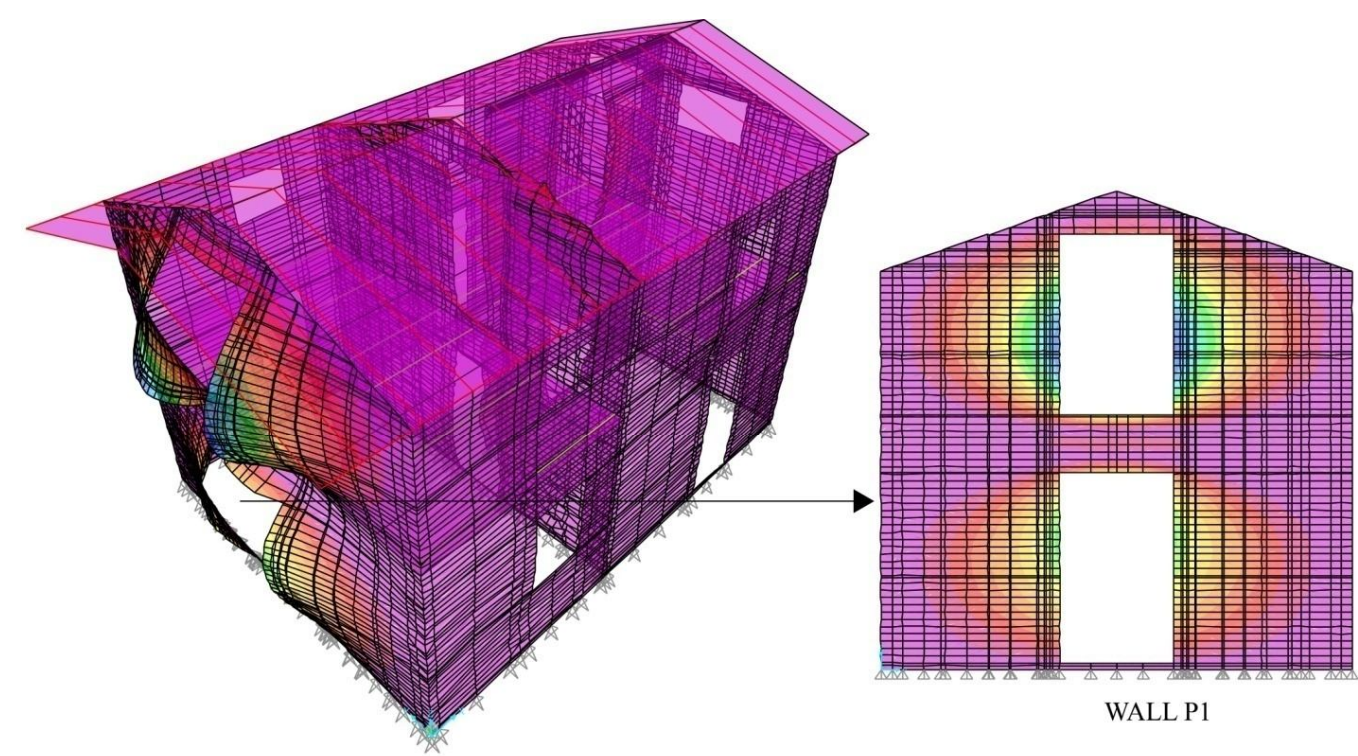

0.190 .380 .570 .760 .951 .141 .331 .521 .711 .902 .092 .282 .472 .66

Figure 11- First natural mode obtained using material properties defined in EN338 (2009) (deformation in $\mathbf{m}$ )

To represent the cross wall intersections, zero-mass link elements were assigned to the nodes of the corners of the log house. Apart from translation along the $\mathrm{X}$ and $\mathrm{Y}$ directions, the directional properties of these links elements were fixed. The introduction of link elements to simulate the function of cross wall connections resulted in a model which was much stiffer, with a natural period of $0.129 \mathrm{~s}$, which is $30.3 \%$ smaller than the observed value. The mode shapes and periods in this cases were not in agreement with those determined by processing the data from the dynamic characterization tests. The links severely restricted the movement of the walls and hence only the gables were free to move. The mode shapes and the natural periods of the first three modes obtained from the modal analysis in this case have been presented in Figure 12. 


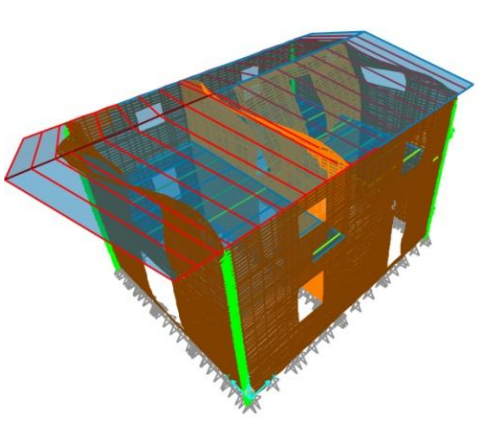

$\mathrm{T}=0.129 \mathrm{~s}$ TRANSLATION-X

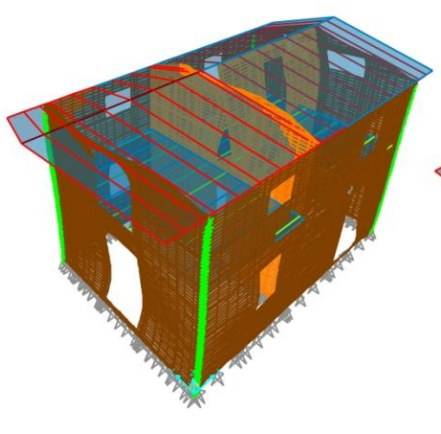

$\mathrm{T}=0.057 \mathrm{~s}$ TRANSLATION-X

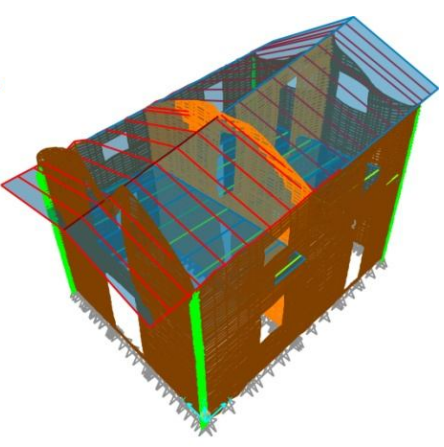

$\mathrm{T}=0.053 \mathrm{~s}$ TRANSLATION-Z

Figure 12-Mode shapes and periods obtained for the case with cross-wall links modelled

The presence of openings in the log house decreases the stiffness of the structure. To prevent the sliding of logs at doors and windows and to increase the strength of the structure, the log house has selftapping screws provided between the $\log$ courses at a distance of about $15 \mathrm{~cm}-20 \mathrm{~cm}$ from the openings. To improve the behaviour of the numerical model in the vicinity of the openings, it was decided to model the mechanical connectors and determine their effect on the structure's performance. The self-tapping screws were modelled as springs with a bi-directional stiffness value given by the slip modulus, $\mathrm{K}_{\text {ser }}$, computed as per EN 1995-1-1:2004.

$$
K_{\text {ser }}=\frac{\rho_{k}^{1.5} d}{23}
$$

Given the characteristic value of the density of the logs, $\rho_{\mathrm{k}}$, is $500 \mathrm{~kg} / \mathrm{m}^{3}$ and the diameter of the screws is $10 \mathrm{~mm}$, the value of the slip modulus per unit length of each fastener is found to be $4861 \mathrm{~N} / \mathrm{mm}$. The mode shapes and the values of the natural periods of the first three modes in this case have been presented in Figure 13. The fundamental period was found to be $0.081 \mathrm{~s}$, which is $56 \%$ less than the experimentally obtained value. In the numerical model, the movement of the building was mainly restricted to the upper floor and the ground floor showed negligible movement. As in the previous case, the results of the modal analysis differed vastly from the modal information obtained experimentally. 


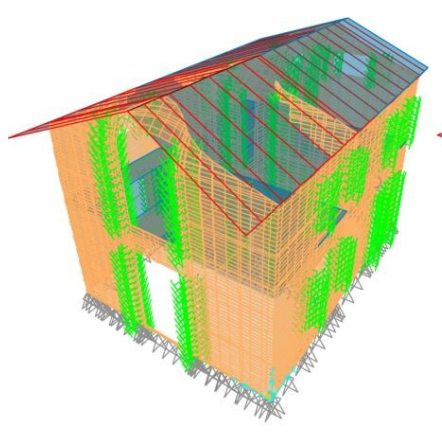

$\mathrm{T}=0.081 \mathrm{~s}$ TRANSLATION-X

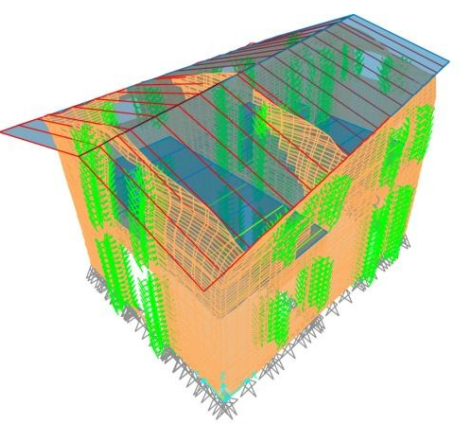

$\mathrm{T}=0.049 \mathrm{~s}$ TORSION

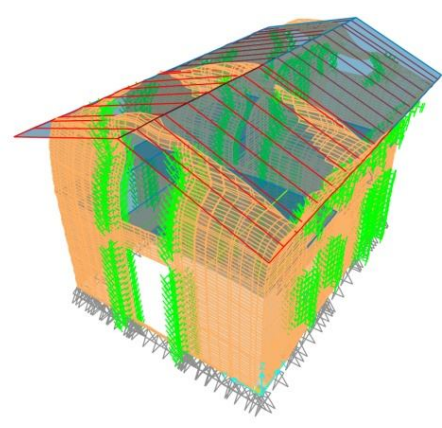

$\mathrm{T}=0.044 \mathrm{~s}$ TRANSLATION-Y

Figure 13-Mode shapes and periods obtained for the case with mechanical connectors around the openings modelled

\section{Conclusions}

The shaking table tests conducted on the two storey log house at LNEC, Portugal, demonstrated that the structure was able to withstand peak ground accelerations up to $0.5 \mathrm{~g}$, without undergoing any major damage. The significant seismic resistance capacity of this structural system reveals its potential to be used as a housing solution in seismic areas. However, the dearth of understanding of the elements that contribute to the load resistance of the log house system has hampered the harnessing of its potential as an earthquake resistant structure.

In this paper, an attempt to develop a numerical model of the log house has been made. The validation of the proposed numerical model has been done by comparing the results of the mode shapes, natural periods and the displacements at selected points with the values obtained from the shaking table tests performed on the full-scale specimen. Owing to the difficulty in the incorporation of the effects of friction in the model, the model did not explore the contribution of friction to the seismic load resistance. The idealization of the notched logs and the corner connections to well-connected rectangular shell elements seems to adequately represent the behaviour of the house. This simplification is justified because the cross-wall connections and the interlock of the tongue and groove profiles of the adjacent logs remained intact during all the tests. While the definition of the mechanical connectors in the modelling of individual $\log$ walls is necessary in order to replicate the real-life loading behaviour (Scott et al., 2005), the mechanical connections of the entire log house were not included as they were found to cause a very high increase in stiffness and vastly restrict the movement of the log walls. The numerical model was not able to replicate 
the exact behaviour of the real-life structure but resulted in a very close match for the modes that were obtained experimentally.

The task of seamlessly integrating and incorporating the interaction between individual structural components was found to be complicated. Sophisticated numerical models of these structures can be developed only after carrying out tests on additional full-scale specimens and subjecting them to higher

ground accelerations so that the damage patterns and the different possible failure mechanisms can be identified and evaluated.

\section{ACKNOWLEDGEMENTS}

The research leading to these results has received funding from the European Union's Seventh Framework Programme [FP7/2007-2013] under grant agreement n²27887 (SERIES). 


\section{References}

ARTeMISModal (2013) Structural Vibration Solutions, Aalborg, Denmark.

Bodig J and Jane BA (1982) Mechanics of wood and wood composites. New York: Van Nostrand Reinhold.

Branco JM and Cruz JP (2008) Mechanical characterization of glued laminated wood round logs. Revista da Associação Portuguesa de Análise Experimental de Tensões, 17, pp.101-08 (in Portuguese).URL: http://www-ext.lnec.pt/APAET/pdf/Rev_17_A11.pdf

Branco JM and Araujo JP (2012) Structural behaviour of log timber walls under lateral in-plane loads. Engineering Structures, pp.371-82.URL:http://hdl.handle.net/1822/19907.

Branco JM, Lourenço PB and Aranha CA (2013) Seismic performance assessment of a timber log house. Structures and Architecture: Concepts, Applications and Challenges, Taylor \& Francis Group, London, pp.114-21.

Branco JM, Lourenço PB and Aranha CA (2014) Shaking table tests of a two-storey log house. Proceedings of the ICE - Structures and Buildings, DOI: 10.1680/stbu.14.00017.

Bucur V (2006) Acoustics of wood. Germany: Springer, Springer Series in Wood Science.

CSI (2011). SAP2000 ultimate (v15.0.0) - structural analysis program, Computer \& Structures, Inc., Berkeley, California.

DIN 68364:1979-11 (1979) Characteristic values for wood species; strength, elasticity, resistance. BEUTH (in German).

EN 1194:1999 (1999) Timber structures. Glued laminated timber. Strength classes and determination of characteristic values. European Committee for Standardisation, CEN, Brussels.

EN 12369-1:2001 (2001) Wood-based panels- Characteristic values for structural design - Part 1: OSB, particleboards and fibreboards. European Committee for Standardisation, CEN, Brussels.

EN 1995-1-1:2004 (2004) Eurocode 5: Design of timber structures - Part 1-1: General - Common rules and rules for buildings. CEN, Brussels, 2004.

EN 1998-1:2004 (2004) Eurocode 8: Design of structures for earthquake resistance - Part 1: General rules, seismic actions and rules for buildings. CEN, Brussels.

EN338:2009 (2009) Structural Timber: Strength Classes. European Committee for Standardisation, CEN, Brussels. 
ETAG 012 (2002) Log Building Kits: Guideline for European Technical Approval. European Organization for Technical Approvals.

Gorman TM and Shrestha D (2002) Shear tests for log home walls. Session 5: testing and analysis of large scale wood structural systems. Presentation at the Forests Products Society Annual Meeting. Madison, Wisconsin.

Graham DA, Carradine DM, Bender DA and Dolan DJ (2010) Performance of log shear walls subjected to monotonic and reverse-cyclic loading. Journal of Structural Engineering, 136(1), pp.37-45.

Hearmon RFS (1948) The elasticity of wood and plywood. Forest Products Research Special Report No. 7, London.

Hirai T, Kimura T, Yanaga K, Sasaki Y and Koizumi A (2004) Lateral resistance of log constructions, In Proceedings of the 8th world conference on timber engineering, WCTE, Lahti, Finland, pp. 251-254.

Hirai T, Meng Q, Sawata K., Koizumi A, Sasaki Y and Uematsu T (2008) Some aspects of frictional resistance in timber construction. In Proceedings of the 10th World Conference on Timber Engineering, 2008. Miyazaki, 2008.

Machado JS and Monteiro G (1997) Madeira para construção - M4:Casquinha. LNEC, Lisbon (in Portuguese).

Mendes L (2009) LNEC-SPA Signal Processing and Analysis tools. In: National Laboratory of Civil Engineering, Lisbon.

Popovski M (2002) Testing of lateral resistance of handcrafted log walls Phase I and II. Forintek Canada Corp., Vancouver, BC.

Scott RJ, Leichti RJ and Miller TH (2005) Finite-element modeling of log wall lateral force resistance. Forest Products Journal, vol. 55, no. 9, September, pp. 48-54.

Testoni M (2012) Shaking table test of a building wood log house: design and execution. Master's thesis (In Italian). Trento, Italy: University of Trento. 
